\title{
Инициирование электрического разряда в воде тонкослойным проводником
}

\author{
*А. П. Смирнов, В. Г. Жекул, О. В. Хвощан \\ Институт импульсных процессов и технологий НАН Украинь,, \\ 2. Николаев, 54018, Украина, ${ }^{*}$ e-mail: smirnovap1978@gmail.com \\ Поступила в редакцию 07.09.2020 \\ После доработки 01.12.2020 \\ Принята к публикации 08.12.2020
}

\begin{abstract}
Представлены результаты экспериментальных исследований волны давления, генерированной подводным электрическим разрядом, который был инициирован тонкослойным проводником леской с тонким внешним слоем меди. Исследования проводились на двух режимах, параметры которых обеспечивали кратковременный и длительный тип разряда. Леска с тонким внешним слоем меди является перспективным методом инициирования подводного электрического разряда. Его использование позволяет уменьшить время предпробойной стадии и предпробойные потери, стабилизировать в пространстве процесс протекания электрического разряда, повысить эффективность электроразрядного воздействия. Отмечено, что в случае реализации кратковременного типа разряда генерируется волна давления, амплитуда которой соизмерима с волной давления при инициировании тонким сплошным медным проводником, и при этом наблюдается более чем двукратное повышение амплитуды генерированной волны давления с увеличением длины лески от 20 до 50 мм по экспоненциальной зависимости. Проведенные исследования также показали, что леска с тонким медным внешним покрытием обладает хорошей стойкостью к воздействующим факторам подводного электрического взрыва.
\end{abstract}

Ключевые слова: электрический взрыв проводника, подводный искровой разряд, амплитуда волны давления, межэлектродное расстояние, инициирование электрического разряда, тонкослойный проводник

УДК 537.528

https://doi.org/10.52577/eom.2021.57.2.15

\section{ВВЕДЕНИЕ}

Во многих направлениях человеческой деятельности в качестве инструмента для достижения поставленной цели используется волна давления. Она, например, применяется в различных технологиях машиностроения, в горной и нефтедобывающей промышленности. Волна давления позволяет деформировать и разрушать, очищать и измельчать. Существуют различные способы генерирования волн давления - соударение тел, использование взрывчатых веществ, ультразвук и целый ряд других. Одним из перспективных направлений, позволяющих получить волну давления в жидкости, является электрический разряд [1-3]. Электрический разряд в жидкости как источник волны давления применяется во многих отраслях промышленности [4]. Этот способ получения волн давления является экологически чистым, отличается возможностью многократного воздействия на объект и позволяет генерировать волны давления в широком диапазоне амплитудно-временных параметров.

\section{АНАЛИЗ ПРОБЛЕМЫ}

Электрический разряд в жидкости может быть реализован либо высоковольтным пробоем межэлектродного водного промежутка (подводным искровым разрядом - ПИР) [1], либо электрическим взрывом проводника (ЭВП), который замыкает межэлектродный промежуток [5-7]. В большинстве электроразрядных технологий используется ПИР. ПИР отличает относительная конструкционная простота его обеспечения и эффективность воздействия. В тоже время при ПИР наблюдается нестабильность параметров возбуждаемых им акустических импульсов (волн давления), которая связана с изменением геометрии канала разряда от импульса к импульсу [8]. Кроме того, при ПИР возникают трудности зажигания разряда с последующим пробоем промежутка при определенных внешних условиях (в жидкостях при повышенных давлениях, в жидкостях с достаточно большой и крайне малой электропроводностью) и поддержания эффективности обработки объекта в жидкости с меняющейся в процессе работы электропроводностью. Еще одной особенностью ПИР является наличие затрат энергии на предпробойной стадии разряда, которые могут быть существенными и при определенных условиях достигать половины и более запасенной энергии, в результате чего существенно уменьшается эффективность воздействия на объект. Этих недостатков лишен ЭВП. Использование металлического проводника в качестве инициатора электри- 
ческого разряда позволяет осуществить стабильный электрический разряд в жидкостях с различной электропроводностью и при повышенных гидростатических давлениях, повысить эффективность воздействия на объект за счет минимизирования энергозатрат на предпробойной стадии разряда и увеличения амплитуды волны давления. Однако масштабное применение металлического проводника в электроразрядных технологиях сдерживается трудностями в разработке надежного механизма его подачи в межэлектродный промежуток при многоимпульсных режимах с высокой частотой разрядов. В связи с этим актуальными являются работы по поиску альтернативного инициатора подводного электрического разряда, который совместит положительные свойства взрыва металлического проводника и упростит возможную реализацию механизма подачи. Таким инициатором могут являться тонкослойные проводники. Примером такого проводника может служить монофильная нить (капроновая леска, в дальнейшем просто леска) с нанесенным электрохимическим способом на ее поверхность тонким слоем меди. Ее внешний слой меди позволяет инициировать электрический разряд, а внутренняя изоляционная основа должна облегчить возможность ее подачи в межэлектродный промежуток. Однако на данный момент отсутствует информация о стабильности и эффективности такого способа инициирования, а также о параметрах генерированной в этом случае волны давления. Особый интерес представляет ее амплитуда. Именно амплитуда генерированной электрическим разрядом в жидкости волны давления для многих электроразрядных технологий является фактором, определяющим эффективность воздействия на объект [9].

Учитывая все вышесказанное, цель данной работы - исследование амплитуды волны давления, генерированной подводным высоковольтным разрядом, который был инициирован тонкослойным проводником- леской с внешним медным слоем.

\section{ЭКСПЕРИМЕНТАЛЬНЫЙ СТЕНД И МЕТОДИКА \\ ЭКСПЕРИМЕНТАЛЬНЫХ ИССЛЕДОВАНИЙ}

Исследования волн давления, генерированных подводным высоковольтным разрядом, который был инициирован леской с внешним медным слоем, проводились на экспериментальном стенде, описанном в [8]. Экспериментальный стенд состоит из трех частей: энергетической, технологической и измерительной.
Энергетическая часть стенда включает в себя оборудование для осуществления высоковольтного электрического разряда и в ходе эксперимента должна обеспечивать установку требуемых параметров разрядного контура (напряжение и емкость).

Электрический разряд осуществлялся в технологической части экспериментального стенда - разрядной камере (рис. 1). Внутренний диаметр разрядной камеры составляет 164 мм, внешний диаметр - 365 мм.

Преобразование электрической энергии в механическую и ввод энергии, запасенной конденсаторами, в рабочую среду при взрыве лески с медным покрытием осуществлялись в электродной системе. Электродная система, которая использовалась в данной работе, приведена на рис. 2а. Для обеспечения хорошего контакта между проводником и электродами электродной системы (анод и катод) электроды были оснащены специальными пружинными контактами (рис. 2б).

Для измерения параметров волны давления использовался волноводный пьезоэлектрический датчик импульсного давления типа ДТХ-1 [10], который был разработан в Институте импульсных процессов и технологий НАН Украины. Внешний вид датчика представлен на рис. 3. Датчик давления ДТХ-1 позволяет исследовать временной профиль волн сжатия, источником которых является электрический разряд в воде, в закрытых объемах жидкости с максимальным амплитудным значением до 150 МПа.

Датчик ДТХ-1 крепился в специальное отверстие на боковой стенке разрядной камеры в экваториальной плоскости к каналу разряда. Общий вид установленного датчика давления и схема его крепления приведены на рис. 4.

В ходе выполнения работ применялось несколько датчиков давления с разной чувствительностью.

Одновременно с измерением волны давления осуществлялось осциллографирование временного профиля разрядного тока и напряжения на разрядном промежутке. Для получения сигналов использовались: омический коаксиальный шунт (с сопротивлением 0,00068 Ом) для измерения разрядного токаи делитель напряжения типа PVM-2 компании NorthStar (коэффициент деления 1:1000) для измерения напряжения на разрядном промежутке.

Для регистрации всех сигналов применялся цифровой четырехканальный осциллограф OWONXDS 3104E. 


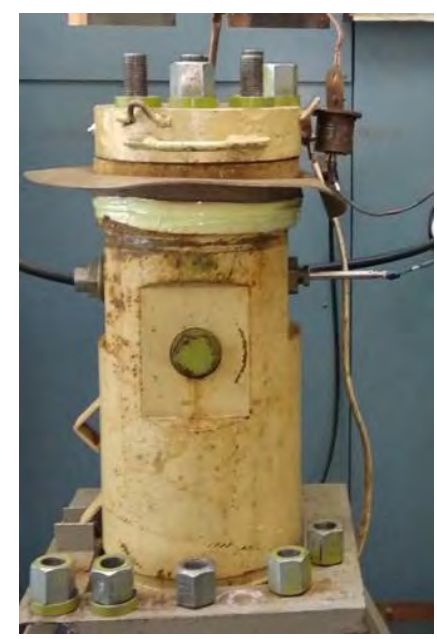

Рис. 1. Разрядная камера.

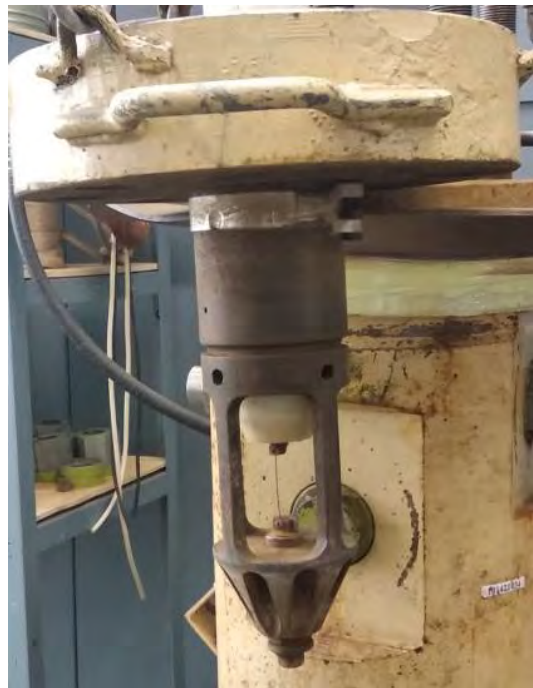

(a)

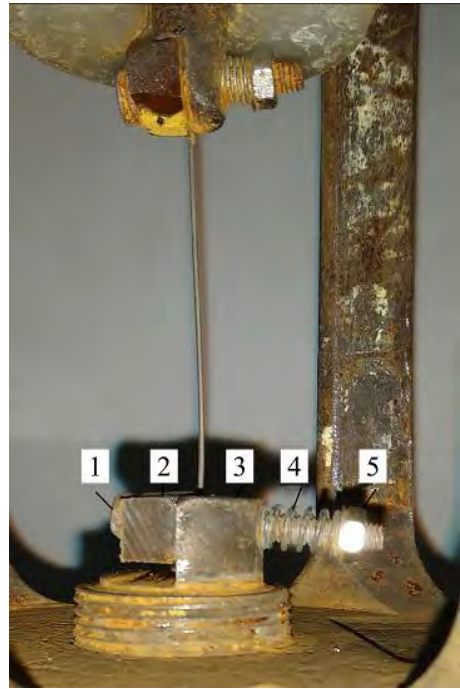

(б)

Рис. 2. Электродная система с модернизированными электродами: внешний вид электродной системы в верхнем фланце разрядной камеры, с закрепленной между электродами леской (а); схема крепления лески на катоде, идентичная схеме крепления на аноде (б): 1 - винт; 2 - диэлектрическая прижимная накладка; 3 - катод; 4 - прижимная пружина; 5 - затягивающая гайка.

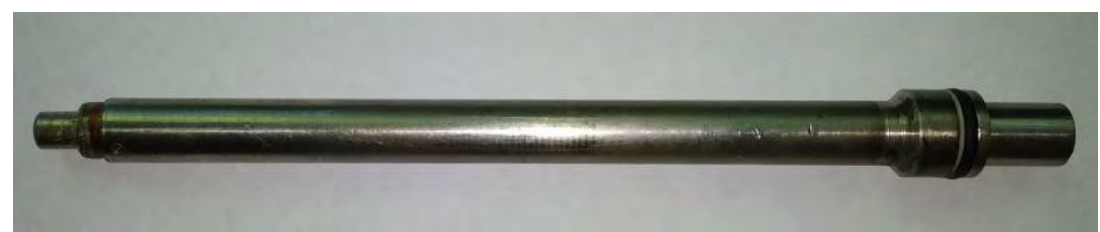

Рис. 3. Внешний вид волноводного пьезоэлектрического датчика импульсного давления типа ДТХ-1.

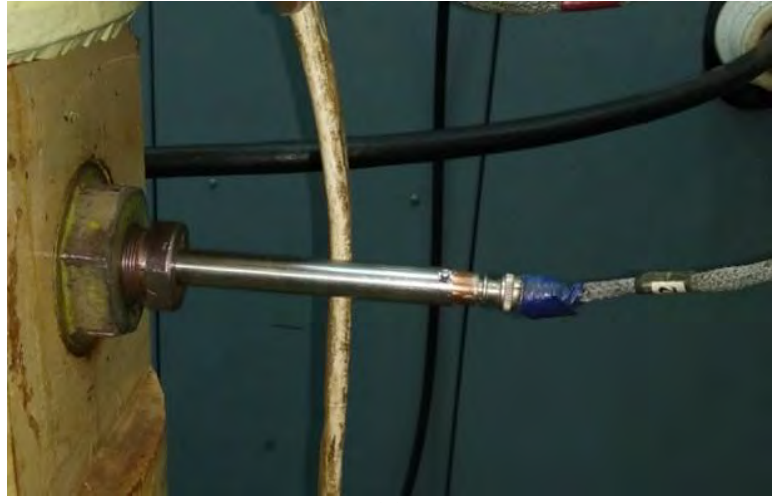

(a)

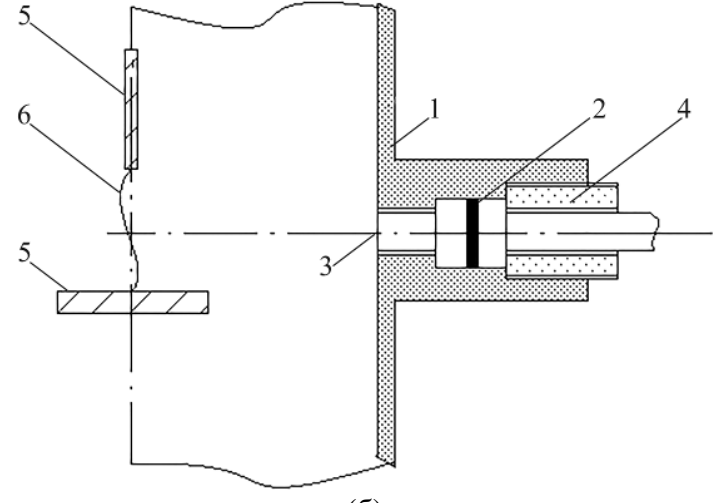

(б)

Рис. 4. Схема крепления датчика на корпусе разрядной камеры: внешний вид (а); схема крепления (б): 1 - корпус разрядной камеры; 2 - уплотнительное резиновое кольцо; 3 - донышко датчика; 4 - прижимная гайка; 5 - электроды; 6 - канал электрического разряда. 


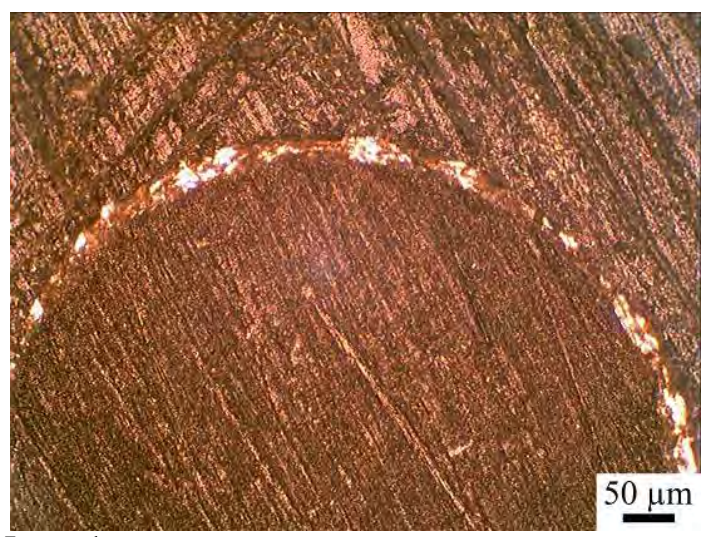

Рис. 5. Профиль лески с медным покрытием в радиальном сечении.

Таблица. Параметры экспериментальных режимов

\begin{tabular}{|c|c|c|c|c|c|c|}
\hline $\begin{array}{c}\text { Номер эксперимен- } \\
\text { тального режима }\end{array}$ & $\begin{array}{c}U_{3}, \\
\mathrm{\kappa B}\end{array}$ & $\begin{array}{c}C, \\
\text { мкФ }\end{array}$ & $\begin{array}{c}L, \\
\text { мкГн }\end{array}$ & $\begin{array}{c}R, \\
\text { Oм }\end{array}$ & $\begin{array}{c}W_{0}, \\
\text { Дж }\end{array}$ & $\begin{array}{c}\tau, \\
\text { мкс }\end{array}$ \\
\hline 1 & 30 & 5 & 3,93 & 0,072 & 2250 & 13,9 \\
\hline 2 & 10 & 95 & 4,011 & 0,037 & 4750 & 61,3 \\
\hline
\end{tabular}

Экспериментальные исследования проводились при нормальном гидростатическом давлении без дополнительного нагрева рабочей жидкости. Электропроводность воды в разрядной камере составляла $\approx 0,04 \mathrm{CM} / \mathrm{M}$. В качестве инициатора использовалась леска, покрытая слоем меди, с внешним диаметром $\approx 0,9$ мм. На рис. 5 приведен ее профиль в радиальном сечении. Леска с медным покрытием является двухслойным материалом - внутренний изоляционный стержень и внешний проводящий медный слой толщиной $\approx 20-25$ мкм, площадь сечения медного слоя $\approx 6 \times 10^{-8} \mathrm{M}^{2}$. Длина лески в экспериментах варьировалась от 20 до 50 мм с шагом 10 мм.

В зависимости от характерного времени выделения энергии $\tau$ (1) электрические разряды могут быть разделены на кратковременные (быстрые) - $\tau \leq 40$ мкс и длительные $\tau>40$ мкс [9]:

$$
\tau=\pi \sqrt{L C}
$$

где $L$ - индуктивность разрядного контура, Гн; $C-$ емкость конденсаторной батареи, $\Phi$.

Учитывая вышеприведенную классификацию, экспериментальные исследования взрыва лески с медным покрытием проводились на двух экспериментальных режимах. При параметрах разрядного контура первого экспериментального режима осуществлялись кратковременные (быстрые) электрические разряды, при параметрах второго - длительные электрические разряды. Параметры экспериментальных режимов приведены в таблице. В ней были приняты следующие обозначения: $U_{3}$ - зарядное напряжение, кВ; $C$ - емкость конденсаторной батареи, мкФ; $L-$ индуктивность разрядного контура, мкГн; $R$ - сопро- тивление разрядного контура, Ом; $W$ - запасенная энергия, Дж; $\tau$ - характерное время выделения энергии, мкс.

Для каждого эксперимента, характеризующегося фиксированными параметрами разрядного контура и геометрическими размерами лески, выполнялась серия из пяти разрядов. После каждого разряда производилась замена лески.

\section{ПОЛУЧЕННЫЕ РЕЗУЛЬТАТЫ}

При осуществлении электрического разряда в воде, который был инициирован леской с медным внешним покрытием, генерируется волна давления. При этом временной профиль волны давления, генерированной при параметрах экспериментального режима №1 (рис. 6а), существенно отличается от временного профиля волны давления, генерированного на режиме №2 (рис. 6б).

При параметрах режима №1 генерируется волна давления, которая характеризуется крутым фронтом нарастания (менее 5 мкс) и резким спадом до величины менее $\approx 20 \%$ от ее амплитудного значения. При этом длительность импульса от начала возрастания до 20\% величины амплитуды на ее спаде $\approx 10$ мкс. Волну давления, которая генерируется на экспериментальном режиме №2, также характеризует крутой фронт нарастания. В то же время ее временной профиль отличают всплески давления на спаде основного импульса и значительно большая, в сравнении с режимом №1, длительность - 20 мкс. Эти отличия результатов, полученных на разных экспериментальных режимах, связаны с изменением параметров разрядного контура. Увеличение емкости конденсаторной батареи и снижение величины 


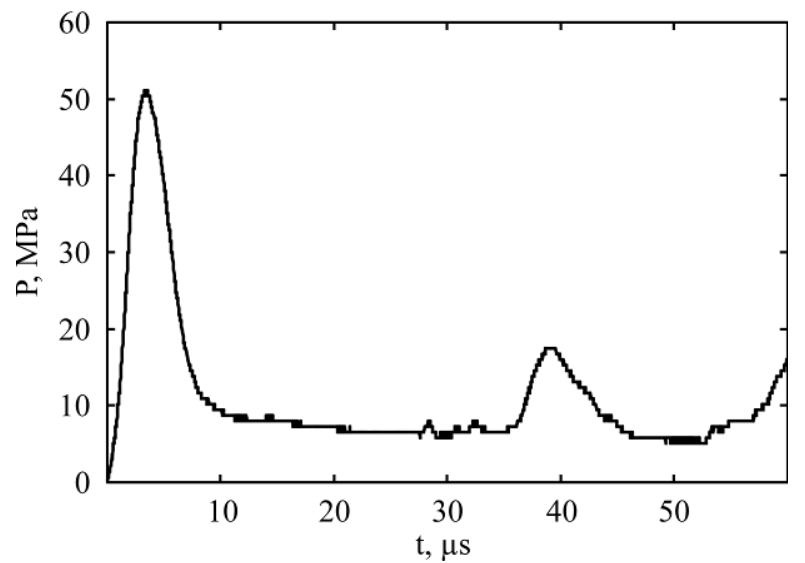

(a)

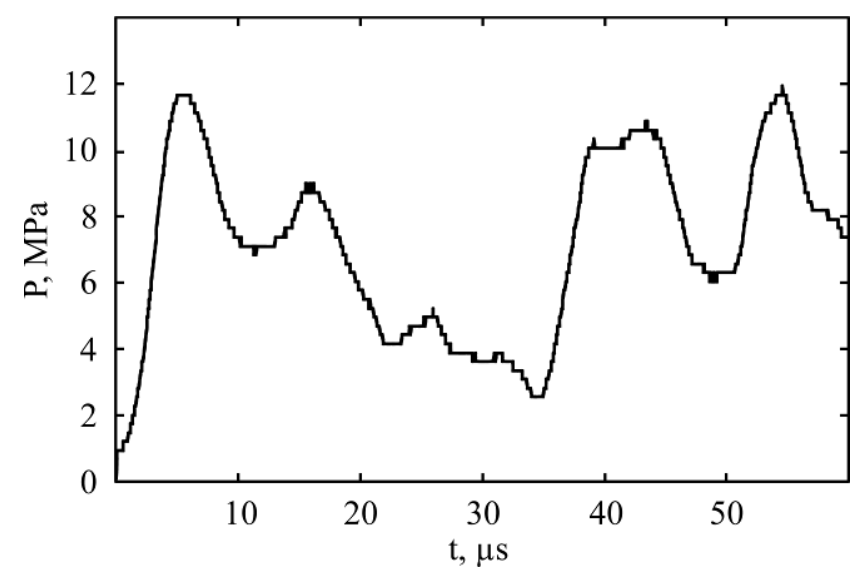

(б)

Рис. 6. Временной профиль волны давления, генерированной электрическим разрядом, инициируемым омедненной леской с внешним диаметром 0,9 мм и длиной 40 мм: экспериментальный режим №1 (а); экспериментальный режим №2 (б).

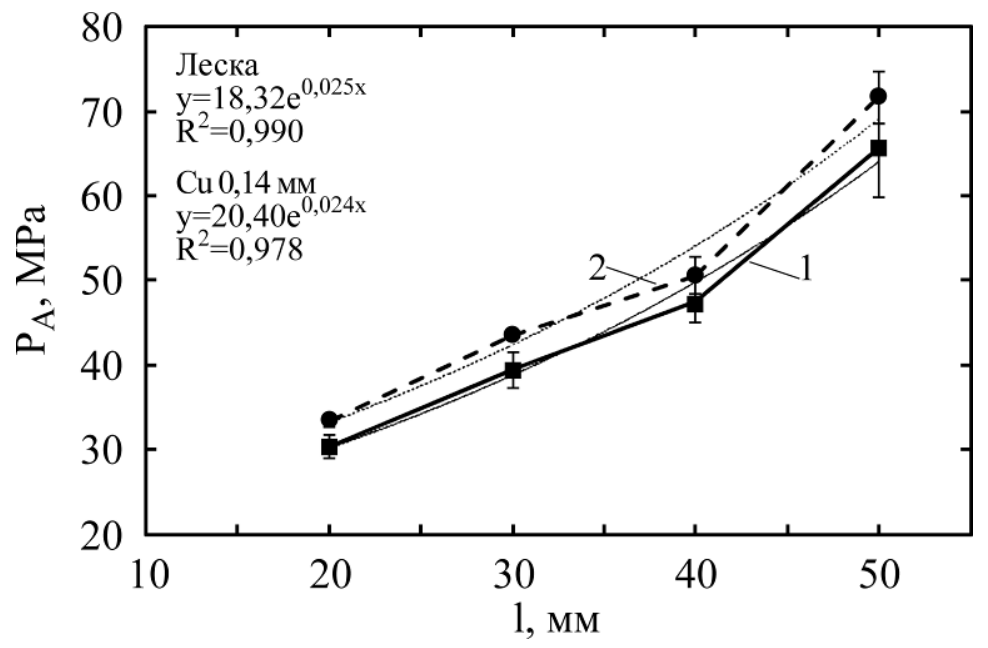

Рис. 7. Зависимость амплитуды волны давления, генерированной инициированным электрическим разрядом, при параметрах экспериментального режима №1: 1 - инициатор - леска с медным внешним покрытием; 2 - инициатор проводник $\mathrm{Cu}$ диаметром 0,14 мм.

зарядного напряжения привели к увеличению длительности и уменьшению скорости ввода энергии, а соответственно и к уменьшению амплитудного значения импульса давления при параметрах экспериментального режима №2 в сравнении с результатами, полученными при параметрах режима №1. Это также привело к увеличению длительности импульса и к медленному и неравномерному сгоранию слоя меди на леске.

Различия заметны и при исследовании зависимостей амплитуды волны давления $\left(P_{\max }\right)$ от длины взрывающейся омедненной лески $(l)$ на разных экспериментальных режимах (рис. 7 и 8).

Представленные на рис. 7 результаты показали, что при параметрах режима №1 с увеличением длины омедненной лески от 20 до 50 мм наблюдается увеличение амплитуды генерируемой волны давления. Данную зависимость можно удовлетворительно описать с помощью экспоненциальной функции (коэффициент достоверности аппроксимации $\left.R^{2}=0,99\right)$. Данная тенденция увеличения вызвана как повышением массы меди, участвующей в процессе электрического взрыва с увеличением длины проводника (эта зависимость является линейной), так и приближением к оптимальному значению длины межэлектродного промежутка. Согласно [9] оптимальная длина промежутка для подводного электрического разряда может быть рассчитана по выражению (2). Для экспериментального режима №1 оптимальная длина межэлектродного промежутка при инициировании электрического разряда тонким металлическим проводником составляет $\approx 0,055$ м (55 мм):

$$
l_{0}=0,36\left(r^{2} z W / A\right)^{0,25} \text {, }
$$

где $r$ - расстояние от оси разряда до стенки разрядной камеры, $\mathrm{M} ; \quad z=\sqrt{L / C}-$ волновое сопротивление контура; $W=0,5 C U_{\Pi}^{2}-$ энергия разряда, Дж; $C$ - емкость конденсаторной батареи, $\Phi ; L \quad$ - индуктивность разрядного контура, Гн; $U$ - напряжение пробоя, В; $A$ - искровая постоянная (величина искровой постоянной для свободного искрового разряда - 


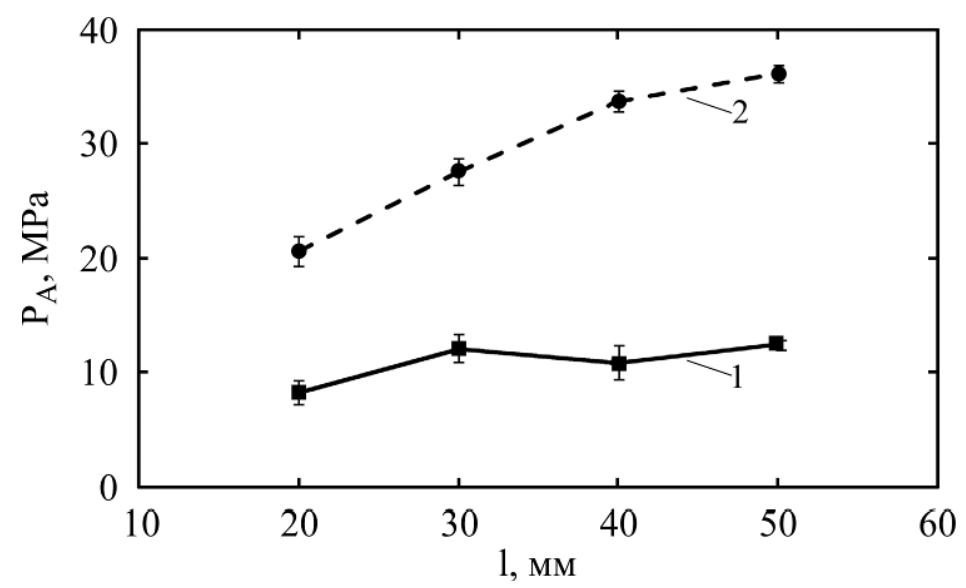

Рис. 8. Зависимость амплитуды волны давления, генерированной инициированным электрическим разрядом, при параметрах экспериментального режима №2: 1 - инициатор - леска с медным внешним покрытием; 2 - инициатор проводник $\mathrm{Cu}$ диаметром 0,14 мм.

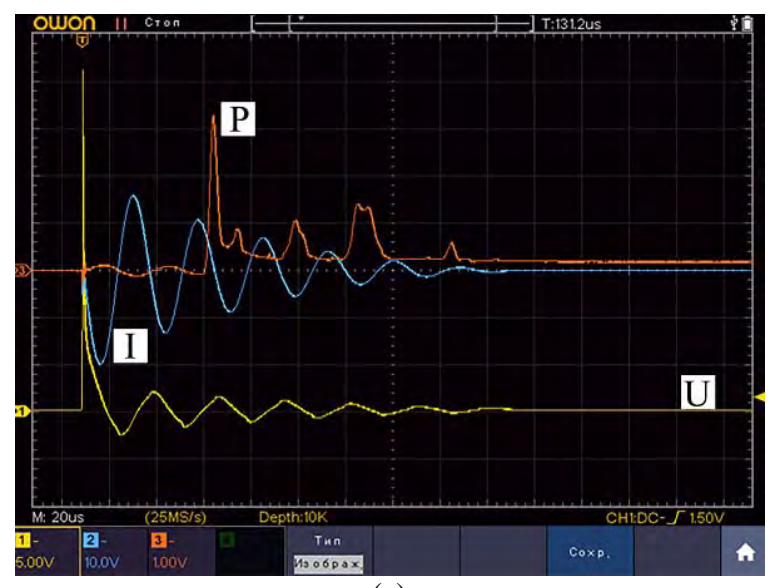

(a)

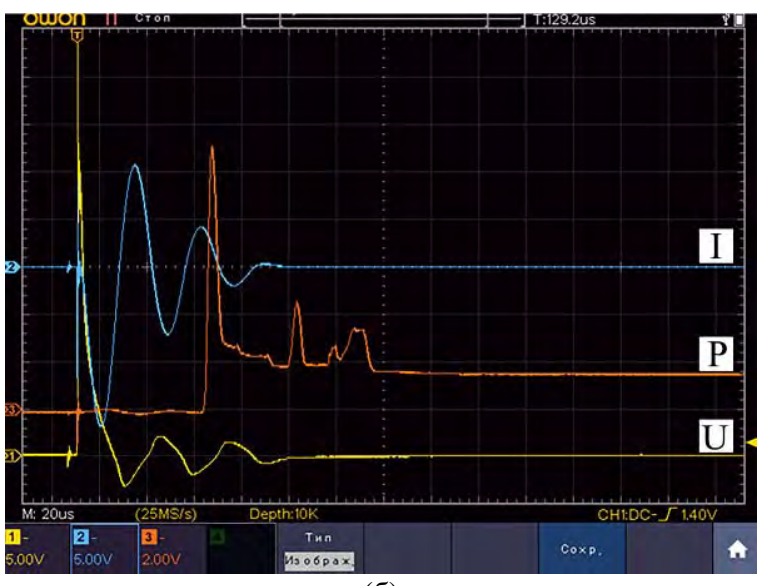

(б)

Рис. 9. Типичные осциллограммы параметров электрического разряда при инициировании омедненной леской внешним диаметром 0,9 мм на экспериментальном режиме №1: $l=20$ мм, $K_{P}=9,131 \mathrm{MПа} / \mathrm{B}(\mathrm{a}) ; l=50$ мм, $K_{P}=6,7057 \mathrm{MПа} / \mathrm{B}$ (б).

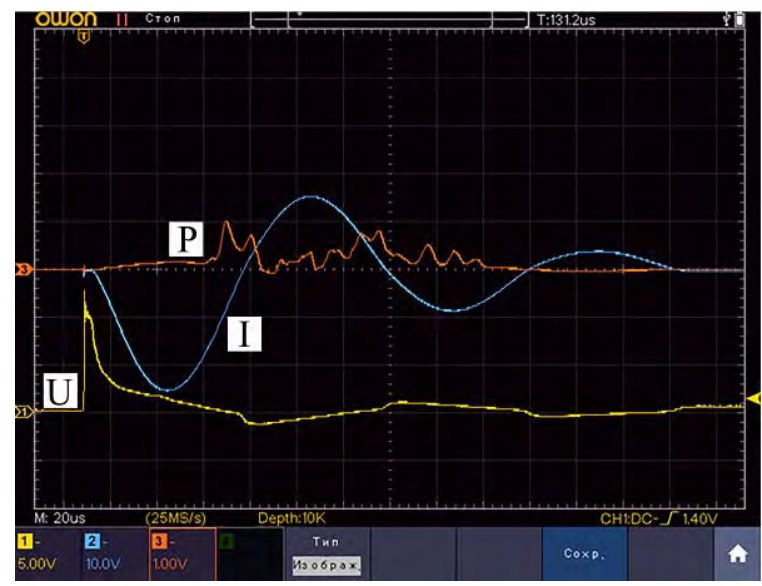

(a)

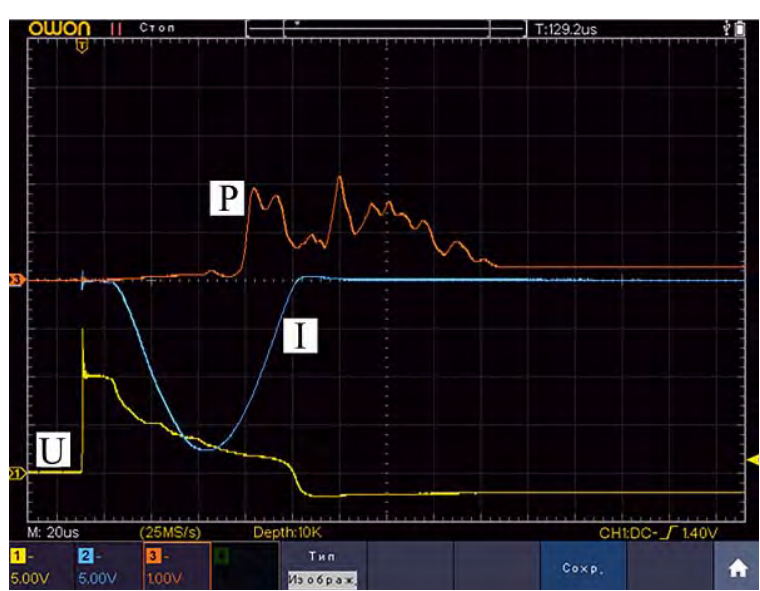

(б)

Рис. 10. Типичные осциллограммы параметров электрического разряда при инициировании омедненной леской внешним диаметром 0,9 мм на экспериментальном режиме №2: $l=20$ мм, $K_{P}=9,131 \mathrm{MПа} / \mathrm{B}(\mathrm{a}) ; l=50$ мм, $K_{P}=6,7057$ МПа/В (б).

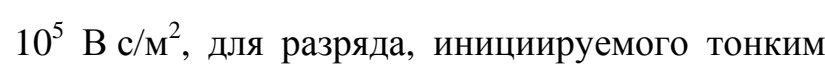
проводником, $\left.-0,25 \times 10^{5} \mathrm{~B} \mathrm{c} / \mathrm{M}^{2}\right)$.

Результаты, полученные при параметрах режима №2 (рис. 8), показывают, что по мере увеличения длины от 20 до 50 мм также наблюдается тенденция к возрастанию амплитуды волны давления. При этом наблюдается уменьшение амплитуды генерированной волны в сравнении с режимом №1 (в $\approx 3$ раза и более, в зависимости от длины лески). Это связано с совокупностью влияния различных факторов. Главными являются параметры разрядного контура, а именно относительно небольшая величина напряжения пробоя и большая емкость, в результате чего реализуется длительный разряд с меньшей скоростью нарастания тока и увеличением характерного времени выделения энергии (в сравнении с режимом №1). 
Анализируя электрический взрыв лески с тонким медным покрытием, нельзя не отметить малый разброс полученных экспериментальных данных (среднее квадратичное отклонение менее $10 \%$ на режиме №1 и менее $14 \%$ на режиме №2). Это выгодно отличает описанный режим электрического взрыва от режима электрического взрыва без инициирования (ПИР) - в работе [8] среднее квадратичное отклонение экспериментальных данных для случая свободного искрового разряда составляет $\approx 19 \%$.

В плане оценки эффективности применения в качестве инициатора электрического разряда лески с медным покрытием представляет интерес анализ протекания электрических процессов разрядного тока и напряжения на разрядном промежутке. На рис. 9 и 10 приведены типичные осциллограммы разрядного тока, напряжения на разрядном промежутке и волны давления при электрическом разряде в жидкости, который был инициирован леской с медным покрытием при параметрах экспериментального режима №1 и экспериментального режима №2 соответственно. На рис. 9 и 10 приняты следующие обозначения: $U$ - напряжение на разрядном промежутке; $I$ - разрядный ток; $P$ - давление на стенке разрядной камеры. В подрисуночной подписи также приведен коэффициент преобразования датчика давления $K_{P}$.

Анализируя рис. 9, можно отметить отсутствие потерь энергии на стадии формирования канала разряда, что положительно сказывается на эффективности воздействия и отличает его в лучшую сторону от «свободного» электрического разряда в жидкости. Можно отметить, что при данных параметрах разрядного контура увеличение длины омедненной лески приводит к изменению временного профиля разрядного тока. С увеличением длины лески от 20 до 50 мм наблюдается увеличение декремента затухания - переход от более колебательного режима к менее колебательному. Анализ временного профиля напряжения на разрядном промежутке и разрядного тока показывает, что их форма близка к предполагаемой форме тока и напряжения при свободном (искровом) электрическом разряде. Однако в отличие от ПИР при инициировании электрического разряда леской с медным покрытием отсутствуют предпробойные потери энергии, что увеличивает эффективность электроразрядного воздействия на объект.

Анализ данных, приведенных на рис. 10, показывает, что при параметрах экспериментального режима №2 реализуется колебательный режим с большим коэффициентом затухания, чем при параметрах режима №1. Причем при длине лески 50 мм может быть реализован апериодический режим, при котором вся энергия выделяется в первый полупериод тока. Соответственно при данных параметрах нецелесообразно дальнейшее увеличение длины омедненной лески. Другим моментом, отличающим разряд на режиме №2, является наличие «полки» напряжения на предпробойной стадии разряда. Длительность задержки пробоя напрямую зависит от длины лески и соответственно от длины межэлектродного промежутка и при длине 50 мм может достигать $\approx 20$ мкс.

Как уже говорилось в самом начале, одна из причин, которая послужила поводом для исследования возможности использования омедненной лески для инициирования электрического разряда,- это упрощение возможности создания надежного механизма ее подачи в межэлектродный промежуток. Поэтому одновременно с исследованием амплитуды волны давления в ходе экспериментальных работ проводилось исследование стойкости инициирующей лески с медным покрытием к факторам, возникающим при осуществлении электрического разряда в жидкости. Стойкость способность материалов или изделий постоянно или длительно противостоять воздействию каких-либо внешних физических или химических факторов [11].

Для определения стойкости лески к факторам электрического разряда в жидкости использовался метод визуального наблюдения за леской после каждого разряда в процессе экспериментальных исследований перед ее заменой. Результаты наблюдения показали, что на всех экспериментальных режимах леска сохраняла свою визуальную целостность. Это говорит о ее стойкости к факторам электрического разряда.

Одним из других способов инициирования электрического разряда является введение в межэлектродный промежуток тонкого инициирующего металлического проводника. При взрыве проводника малого диаметра (тонкого инициирующего) время разрушения проводника по сравнению с длительностью полупериода собственного колебания разрядного контура пренебрежимо мало [1]. Почти вся запасенная в конденсаторах энергия выделяется в канале, образованном продуктами его разрушения, соответственно временной профиль разрядного тока мало отличается от профиля разрядного тока при разряде без инициирования проводником. Аналогичная картина с временным профилем разрядного тока наблюдается и при инициировании леской $\mathrm{c}$ тонким медным внешним слоем. Учитывая все вышесказанное, в данной работе было выполнено сравнение двух типов инициирования - леской с медным 


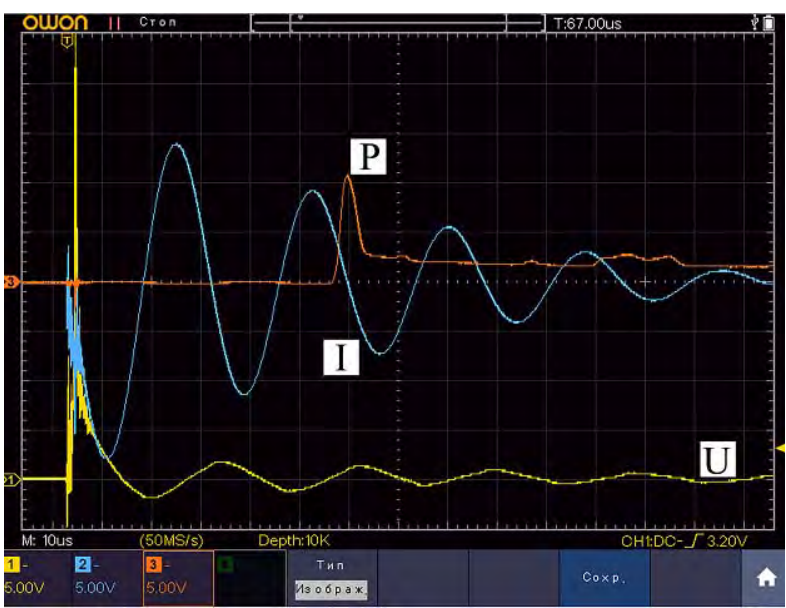

(a)

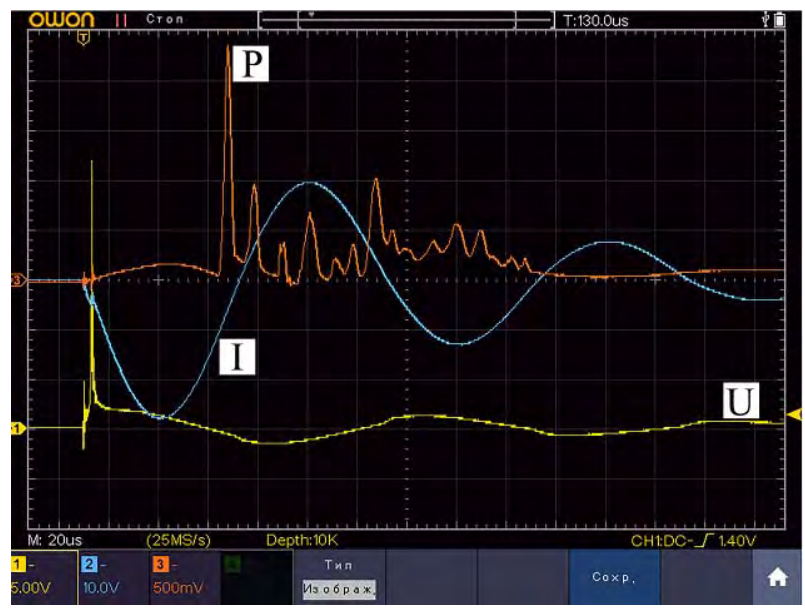

(б)

Рис. 11. Типичные осциллограммы инициирования электрического разряда медным проводником внешним диаметром 0,14 мм, l = 50 мм, $K_{P}=6,7057$ МПа/В: экспериментальный режим №1 (а); экспериментальный режим №2 (б).

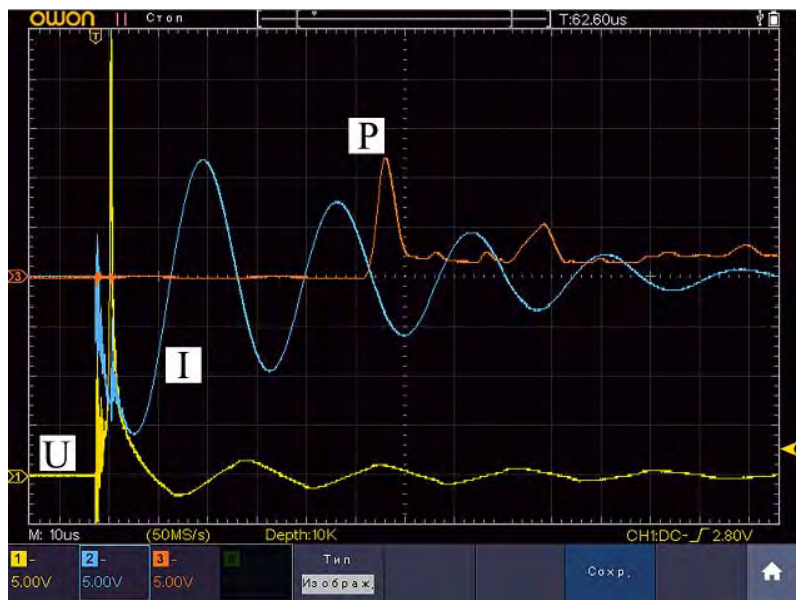

Рис. 12. Типичные осциллограммы инициирования электрического разряда медным проводником внешним диаметром 0,25 мм, $l=50$ мм, $K_{P}=10,64 \mathrm{M \Pi а} / \mathrm{B}$.

внешним покрытием и тонким медным проводником внешним диаметром 0,14 мм (площадь сечения $1,54 \times 10^{-8} \mathrm{M}^{2}$ ).

На рис. 7 и 8 приведены зависимости амплитуд генерированных волн давления от межэлектродного расстояния (соответственно и от длины проводника) при инициировании электрического разряда медным проводником. Анализ данных, которые представлены на рис. 7, показывает, что на экспериментальном режиме №1 и при инициировании омедненной леской, и при инициировании медным тонким проводником генерируются волны давления с близкими значениями амплитуд. Также стоит отметить, что наблюдается идентичность внешнего вида зависимостей - экспоненциальная. В тоже время при параметрах экспериментального режима №2 наблюдается значительное отличие в полученных результатах - при инициировании медным проводником (рис. 8, кривая 2) проявляется четкая тенденция к росту амплитуды волны давления с увеличением межэлектродного расстояния (длины проводника), чего не наблюдается при инициировании леской с медным покрытием (рис. 8, кривая 1).
Кроме того, при параметрах экспериментального режима №2 амплитуда генерированной волны давления при инициировании проводником до 3 раз больше, чем при инициировании омедненной леской.

На рис. 11 приведены типичные осциллограммы электрических процессов при инициировании электрического разряда медным проводником диаметром 0,14 мм для экспериментальных режимов №1 и №2.

Сравнивая результаты, которые были приведены на рис. 11, с данными, представленными на рис. 9 и 10, можно отметить, что на осциллограммах тока и напряжения при инициировании медным проводником наблюдается характерный для взрыва проводника индуктивный пик перенапряжения, которого нет при инициировании омедненной леской. Пик перенапряжения возникает в момент разрушения проводника, что сопровождается ростом сопротивления межэлектродного промежутка [1]. Отсутствие данного явления на осциллограммах при инициировании разряда омедненной леской может свидетельствовать, что в процессе протекания разряда отсутствует разрыв проводящего слоя, 
это служит причиной отсутствия пика перенапряжения. Разряд протекает непрерывно - скорее всего, при частичном разрушении внешнего слоя медного покрытия происходит неполное его испарение до образования сквозного плазменного канала, по которому происходит последующее развитие электрического разряда. В случае полного разрушения медного слоя разряд продолжает развиваться по поверхности лески.

Анализ профиля омедненной лески, которая применялась в экспериментальных исследованиях (рис. 5) показал, что внешний слой меди по величине площади сечения соответствует сплошному медному проводнику диаметром $\approx 0,28$ мм. Поэтому в рамках данной работы для сравнения был выполнен эксперимент по взрыву медного проводника диаметром 0,25 мм и длиной 50 мм при параметрах экспериментального режима №1 (на рис. 12 приведена типичная осциллограмма).

При взрыве медного проводника диаметром 0,25 мм (площадь сечения $\approx 5 \times 10^{-8} \mathrm{M}^{2}$ ) генерируется волна давления с амплитудой 126,26 МПа (среднеквадратическое отклонение 3,5\%). Это в ₹ 1,91 раза больше, чем при инициировании разряда леской с медным внешним покрытием.

\section{ВЫВОДЫ}

Леска с тонким внешним слоем меди является перспективным методом инициирования подводного электрического разряда. Его использование позволит уменьшить время предпробойной стадии и предпробойные энергозатраты, тем самым повысив эффективность электроразрядного воздействия. Кроме того, применение данного способа инициирования стабилизирует в пространстве процесс протекания электрического разряда, делает его менее стохастическим. Это, в свою очередь, приводит к генерированию волн давления с более стабильными амплитудно-временными характеристиками, чем при подводном искровом электрическом разряде.

Полученные экспериментальные результаты по инициированию электрического разряда омедненной леской диаметром 0,9 мм (с толщиной слоя меди от 20 до 25 мкм) показали, что в случае реализации кратковременного типа разряда (экспериментальный режим №1: 30 кВ, 5 мкФ) генери-руется волна давления, амплитуда которой соизмерима с волной давления при инициировании тонким сплошным медным проводником. Однако в случае реализации длительного типа разряда (экспериментальный режим №2: 10 кВ, 95 мкФ) генерируется волна давления, амплитуда которой в несколько раз (в $\approx 3$ раза и более, в зависимости от длины лески) меньше, чем при параметрах экспериментального режима №1,и до 3 раз меньше, чем при инициировании электрического разряда в воде тонким медным проводником (диаметром 0,14 мм).

В случае инициирования леской с тонким внешним медным покрытием электрического разряда при параметрах, которые обеспечивают кратковременный тип электрического разряда, наблюдается повышение амплитуды генерированной волны давления более чем в 2 раза с увеличением длины лески от 20 до 50 мм. Эта зависимость может быть достоверно описана экспоненциальной функцией $\left(R^{2}=0,99\right)$. При реализации длительного типа разряда при увеличении длины лески от 20 до 50 мм наблюдается незначительное повышение амплитуды волны давления (до $\approx 50 \%$ ).

Также результаты экспериментальных исследований показали, что леска с тонким медным внешним покрытием обладает хорошей стойкостью к воздействующим факторам подводного электрического взрыва.

\section{БЛАГОДАРНОСТЬ}

Авторы благодарят к.т.н. А.Д. Зайченко за исследование микроструктуры используемого в экспериментах материала.

\section{ЛИТЕРАТУРА}

1. Кривицкий, Е.В., Динамика электровзрыва в жидкости. Киев: Наукова думка, 1986. 208 с.

2. Yan, D., Bian, D., Zhao, J., Niu, S., Study of the Electrical Characteristics, Shock-Wave Pressure Characteristics, and Attenuation Law Based on Pulse Discharge in Water, Shock and Vibration, 2016, vol. 2016, 6412309. doi: 10.1155/2016/6412309.

3. Курец, В.И., Соловьев, М.А., Жучков, А.И., Барская, А.В., Электроразряднье технологии обработки и разрушения материалов. Томск: Издательство Томского политехнического университета, 2012. 272 с.

4. Вовченко, А.И., 50-летний путь развития: теория и практика электроразрядных процессов. В кн.: Mатериаль ХVI Международной научной конференции «Физика импульсных разрядов в конденсированных средах», 19-22 августа 2013, Николаев, Украина, Николаев: КП "Миколаївська обласна друкарня", 2013, с. 3.

5. Krasik, Ya., Fedotov, A, Sheftman, D., Efimov, S. et. al. Under water electrical wire explosion. Plasma Sources Sci. Technol., 2010, vol. 19, no. 3, 034020. doi: 10.1088/0963-0252/19/3/034020

6. Кортхонджия, В.П., Мдивнишвили, М.О., Саралидзе, 3.К. О природе импульсного давления, создаваемого взрывом проволоки в воде. ЖТФ, 2006, т. 76, № 11, с. 43. 
7. Ben Liu, Deguo Wang, Yanbao Guo, Influence of water conductivity on shock waves generated by underwater electrical wire explosion. Phys. Lett. A, 2018, vol. 382, no. 1, p. 49. doi: 10.1016/j.physleta.2017.10.039

8. Смирнов, А.П., Жекул, В.Г., Мельхер, Ю.И., Тафтай, Э.И. и др. Экспериментальное исследование волн давления, генерированных электрическим взрывом в закрытом объеме жидкости. ЭОМ, 2017, т. 53, № 4, с. 47.

9. Шамко, В.В., Кучеренко, В.В., Теоретические основы инженерных расчетов энергетических $u$ гидродина-мических параметров подводного искрового разряда. Николаев: ИИПТ НАН Украины, $1991.52 \mathrm{c.}$

10. Жекул, В.Г., Смирнов, А.П., Тафтай, Э.И., Хвощан, О.В. и др. Пьезоэлектрический волноводный датчик для измерения импульсного давления в замкнутых объемах жидкости при высоковольтном электрическом разряде. Електротехніка і Електромеханіка, 2017, № 5, c. 55. doi: 10.20998/2074-272X.2017.5.09

11. Рязанцев, В.Д., Большая политехническая энцииклопедия. М.: Мир и Образование, 2011. 704 с.

\section{Summary}

The paper presents the results of experimental studies of a pressure wave generated by an underwater electric discharge which was initiated by a thin-layer conductor a fishing line with a thin outer layer of copper. Experimental studies were carried out in two modes, the parameters of which provided a short and $\phi$ long type of discharge. The results showed that a fishing line with a thin outer layer of copper is a promising method for initiating an underwater electric discharge. Its use allows to reduce the time of the pre-breakdown stage and pre-breakdown losses, to stabilize the process of an electric discharge in space, and to increase the efficiency of the electric discharge effect. It is noted that in the case of a short-term type of discharge, a pressure wave is generated, the amplitude of which is comparable to the pressure wave upon initiation of a thin solid copper conductor, and a two-fold increase of the amplitude of the generated pressure wave with increasing the fishing line length from 20 to $50 \mathrm{~mm}$ in an exponential manner is observed. Studies have also shown that a fishing line with a thin copper outer coating has good resistance to the impact factors of an underwater electric explosion.

Keywords: electrical wire explosion, underwater spark discharge, pressure wave amplitude, inter-electrode gap, initiation of electrical discharge, thin-layer conductor 